\title{
The Effects of Vertical Integration on the Release of New Films*
}

\author{
Claudio A. Agostini ${ }^{\dagger} \quad$ Eduardo H. Saavedra ${ }^{\ddagger}$
}

September 2009

\begin{abstract}
This paper both theoretically and empirically addresses how a vertical structure in the motion-pictures industry determines the number of prints a distributor releases of a new film. A simple theoretical model shows that the optimal number of copies is increasing on the expected demand for the film and the revenue share of the distributor, and decreasing on the cost of each copy. The model also predicts that the optimal number of copies will decrease with the number of theaters that are vertically integrated with the distributor, as long as running a cinema requires financing a non-negligible cost of capital. The theoretical results are empirically tested using a very rich dataset of films exhibition patterns in the major Chilean markets. The empirical results show that, on average, a non-integrated distributor releases 8 more copies than an integrated distributor.
\end{abstract}

JEL: L22, L82, C25.

Keywords: Motion-Pictures, Vertical Integration, Release of New Films

${ }^{*}$ We are thankful to the Cámara Chilena Cinematográfica, and particularly to Rodrigo Kostner, for providing us the data. We also thanks Darlene Chisholm for helpful comments to an earlier version of this paper. Haydée Tejada, Johanna Jiménez and José Fernández provide great research assistance.

${ }^{\dagger}$ ILADES-Universidad Alberto Hurtado, Chile. Email: agostini@uahurtado.cl

${ }^{\ddagger}$ ILADES-Universidad Alberto Hurtado, Chile. Email: saavedra@uahurtado.cl 


\section{Introduction}

Once a movie is produced, it is distributed to theaters for its exhibition. The size of the audience, however, is uncertain and the optimal number of copies to be distributed depends on the expected demand for the film. The distributor of a film chooses a release pattern -the number and location of theaters in which the film is going to be shown- and a date at which to release films for exhibition, looking for high demand periods and seeking to avoid competition from films that are close substitutes. The size of the initial release determines the number of prints needed for distribution to each of the theaters. A wide release on many screens draws a large, simultaneous sample of consumers in many theaters and cities, but the film faces the risk of being played-off rapidly and be dropped from theaters. A tailored release strategy samples consumers sequentially, starting at a few theaters and using the information from that sample to adjust bookings if the film builds an audience (De Vany and Walls (1996)).

The paper both theoretically and empirically addresses the question of what effect has the vertical integration between distributors and exhibitors on the number of copies a distributor releases. For this purpose, a very simple theoretical model is derived and then a count model of films is estimated using a very rich dataset of films released patterns in the major Chilean markets. The results show that vertical integration between distributors and cinemas yields fewer copies than the number of prints released by a non-integrated distributor. The empirical results also show that the number of copies increases with capacity (either screens or seats) and if the film is a sequel. On the other hand, the number of copies 
decreases with the total number of new films nationally released either the same week or the same month.

The literature has studied the release pattern of films and their duration, including how vertical integration might affect either of them. Corts (2001), addresses a similar question to the one addressed in this paper, also related to how the vertical market structure changes the optimal decision in the release pattern of a movie. Using aggregated data from the U.S. film exhibition market, his results show that vertical integration between producers and distributors yields an inefficient release-date scheduling of a film. The programming of first-run films by exhibitors was considered by Chisholm, McMillan and Norman (2006), who show that theaters under common ownership make similar programming choices, but the potential effects of vertical integration were not analyzed. Gil (2007) studies the determinants of vertical integration between distributors and exhibitors based on ex-post contractual costs. The results show that integrated distributors are more likely to distribute films with higher renegotiation frequencies and also more likely to use their own theaters to exhibit them.

The survival of first-run films has been addressed by Chisholm and Norman (2006), who show that the duration is affected by intra-firm and inter-firm strategic choices, and by De Vany and Walls (1997), who found that survival time is strongly related to the number of initial bookings. In both cases the effects of vertical integration were not considered. Finally, $\mathrm{Fu}(2009)$ considers the effect of vertical integration between distributors and exhibitors and finds that films released by integrated distributors are exhibited for shorter periods in 
distributor-owned theaters than in independently owned ones. ${ }^{1}$

The literature has addressed the effects of vertical integration on the released date scheduling of a film, the type of films distributed and also on the duration of films, but to our knowledge there is no empirical evidence on the effects of vertical integration on the release pattern of films and, particularly, on the number of copies a distributor releases. The goal of this paper is to fill this gap and extend the empirical analysis on release patterns to vertical integration, considering some specific characteristics of each film (Oscar nominations and awards, genre, sequels), of the theater where the film is exhibited (capacity), and some characteristics of the market at the time of release (holidays, number of new films released nationally). For this purpose we use a very rich dataset consisting of weekly filmprogramming for an average of 30 theaters in the 11 major cities in Chile during the period January 2001 - December 2004.

The main empirical result of the paper shows that vertical integration towards the exhibition market has a negative impact on the total number of films released by a distributor. On average, a vertically integrated distributor releases 8 less copies of a film than a nonintegrate, keeping constant intra-film, intra-theaters and market characteristics.

The structure of the paper is the following. In the next section we provide a short description of the decision process for scheduling the release of a new film in the motionpicture exhibition market. We describe in section 3 the Chilean distribution and exhibition markets. We present in section 4 a very simple static model for the optimal number of

\footnotetext{
${ }^{1}$ Similarly, the question of what determines the success of a movie is addressed by Bagella and Becchetti (1999), De Vany and Walls (1997), Deucher, Adjamah, and Pauly (2005) and Jansen (2005), for respectively the Italian, American, England, and German markets.
} 
prints that a distributor releases. We describe the data in section 5 and then we show the results in section 6 . Finally, we conclude in section 7 .

\section{Scheduling the Release of a New Film}

The process of selling the right to exhibit a movie in a small country with almost no film industry, like Chile, works as follows. ${ }^{2}$ It starts when the distributors receives information from the main Hollywood studios about movie titles, main actors and dates of release. This information is not sufficient to forecast the potential demand for the movie, but it helps the distributors to estimate what movies are most likely to be a blockbuster or a failure in a specific market. After considering the studios information, the distributors recommend a group of movies to be released in a specific market and the dates for release. With this information, the studios decide the number of copies, dates of release and marketing expenses in each market. Once the distributors know which movies and when are going to be released in the market (line-up), they share the information with exhibitors and determine the share of revenue for themselves. ${ }^{3}$

At that point exhibitors have not decided yet which movies are going to exhibit and which ones will not. When the release date is closer and there is more information about demand (from box office and admissions in other foreign markets), the distributor decides a release strategy for the movie (number and location of theaters where the movie will be

\footnotetext{
${ }^{2}$ Canterbery and Marvasti (2001) provides a an adequate description of the functioning of this market in the U.S. market.

${ }^{3}$ Goettler and Leslie (2005) shows the importance of risk-sharing using the contractual relationship between distributors and exhibitors in the motion-picture market.
} 
exhibited).

The exhibitors play an important role in the decision of the release strategy, because distributors need enough available screens for the release date. If the exhibitors cannot or are not willing to provide such number of screens, then either the release strategy or the date must be modified. Just before the release date then, exhibitors and distributors negotiate the exhibition of a movie. In general, movies are released either Thursdays or Fridays. The release pattern and the number of copies a distributor chooses to release is, therefore, determined mainly by the distributor but considering information provided by the exhibitor.

An interesting broad question is then how different relationships between distributors and exhibitors might affect the release pattern. As it was mentioned before, in this paper we explore a more specific question related to the effects of vertical integration between a distributor and an exhibitor: how the vertical market structure affects the number of copies that the distributor releases into the market.

\section{The Distribution and Exhibition Markets in Chile}

The distribution market in Chile consists of three large companies (Andes Films, UIP, and Fox-Warner) and a fringe of several small independent distributors. Table 1 shows the market shares of the main distributors during the period 1999-2004. In the case of Chilean movies, there exist also some distribution companies that are created with the purpose of distributing a single movie. 
Table 1: Distributors

\begin{tabular}{|c|c|c|c|c|}
\hline & Andes Films & Fox - Warner & UIP & Independents \\
\hline 1998 & $34.0 \%$ & $40.7 \%$ & $21.9 \%$ & $3.4 \%$ \\
\hline 1999 & $29.5 \%$ & $35.2 \%$ & $21.5 \%$ & $13.9 \%$ \\
\hline 2000 & $43.0 \%$ & $26.1 \%$ & $25.6 \%$ & $5.3 \%$ \\
\hline 2001 & $27.2 \%$ & $29.9 \%$ & $29.2 \%$ & $13.7 \%$ \\
\hline 2002 & $32.4 \%$ & $40.1 \%$ & $14.0 \%$ & $13.6 \%$ \\
\hline 2003 & $31.7 \%$ & $36.9 \%$ & $21.3 \%$ & $10.1 \%$ \\
\hline 2004 & $23.5 \%$ & $45.6 \%$ & $21.7 \%$ & $9.3 \%$ \\
\hline
\end{tabular}

The three major distributors have exclusive contracts with Hollywood Studios: Andes Film is the exclusive distributor of Columbia, Disney, and NU Vision; UIP is the exclusive distributor of Universal, Paramount, and DreamWorks; and Fox-Warner is the exclusive distributor of Fox and Warner.

The exclusive contract allows the distributors to distribute movies in Chile only for exhibition on theaters. The contract does not allow the distributors to operate in other exhibition markets like DVDs or Cable TV, but they are allowed to distribute independent films. Figure 1 shows the number of new releases by distributor during the period 1994-2004.

The exhibition market consists of three kind of participants: large international chains (Hoyts, Cinemark, Showcase), smaller national chains (Chilefilms-Cinemundo and Showtime), and small independent theaters. Tables 2 and 3 show the total seating capacity in Chile by exhibitor and the box office revenues for 2004 by type of exhibitor.

One of the interesting characteristics in the Chilean market is related to the property relationships between distributors and exhibitors. Hoyts is a franchising of the Australian chain and in Chile is associated with AMC USA and United Shopping Center Chile. It has 
Figure 1: New Films Released by Distributor

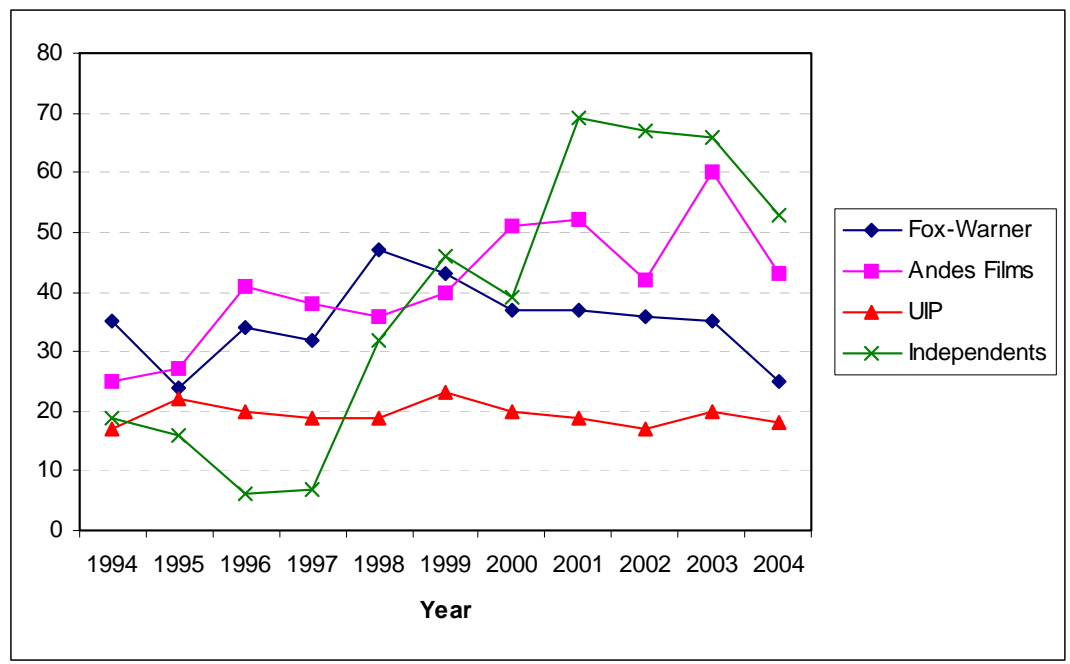

Table 2: Exhibitors' Capacity

\begin{tabular}{|cccc|}
\hline \multicolumn{4}{c}{ Total Capacity in Chile by Exhibitor in 2004 } \\
\hline \multirow{3}{*}{ Cinemundo } & Screens & Seats & Share \\
\cline { 2 - 4 } Cinemark & 46 & 12,166 & $18.34 \%$ \\
Hoyts & 50 & 20,505 & $30.91 \%$ \\
Showcase & 24 & 5,055 & $7.60 \%$ \\
Others & 55 & 17,608 & $26.55 \%$ \\
Total & $\mathbf{2 7 0}$ & $\mathbf{6 6 , 3 2 8}$ & $\mathbf{1 0 0 . 0 0 \%}$ \\
\hline
\end{tabular}

theaters in Santiago ( 5 theaters with 50 screens) and Valparaiso (1 theater with 5 screens).

Cinemark is a franchising of the American chain with 95 screens (39 of them outside of Santiago). Showcase is a subsidiary of National Amusement with 24 screens in Santiago.

Finally, Cinemundo is owned by ChileFilms, the same owner of the distributor Andes Films. 
Table 3: Exhibitors' Admissions and Revenue

\begin{tabular}{|ccccc|}
\hline \multicolumn{3}{|c|}{ Admissions and Gross Box Office by type of Exhibitor in 2004 } \\
\hline & \multicolumn{2}{c|}{ Rest of the Country } & \multicolumn{2}{c|}{ Santiago } \\
\cline { 2 - 5 } & Admissions & GBO $(\mathrm{Ch} \$)$ & Admissions & GBO $(\mathrm{Ch} \$)$ \\
\hline National Chains & $1,086,706$ & $2,451,322,445$ & 208,407 & $496,204,450$ \\
International Chains & $1,934,404$ & $4,095,920,250$ & $4,120,907$ & $9,541,446,740$ \\
Independents & 456,158 & $784,441,700$ & 6,939 & $7,916,566$ \\
Total & $\mathbf{3 , 4 7 7 , 2 6 8}$ & $\mathbf{7 , 3 3 1 , 6 8 4 , 3 9 5}$ & $\mathbf{4 , 3 3 6 , 2 5 3}$ & $\mathbf{1 0 , 0 4 5 , 5 6 7 , 7 5 6}$ \\
\hline
\end{tabular}

\section{The Model}

In this section, a simple model is used to show that theoretically the strategy a distributor chooses in the release of a movie depends, among several factors, on whether the distributor is vertically related or not with exhibitors in the downstream market.

\subsection{Assumptions}

Consider a very simple static model in which there is one distributor, who has the monopoly rights to distribute a movie in a given market, and there are several theaters that may be either owned by the distributor or not. Assume also that the movie may have substitutes in the market, but for simplicity suppose that there is no strategic behavior regarding other distributors' film release decisions.

Let us assume that a mass of consumers are uniformly distributed between 0 and 1 . If there is a cinema located at point $A$ into this interval that shows a movie, then all individuals located at a distance $Q(\theta, P, N)$ on both sides of $A$ go to this cinema. Consumers located beyond $\frac{1}{2} Q(\theta, P, N)$ do not go to this theater. As consumers are uniformly distributed, the demand for watching the movie in a specific cinema is $Q(\theta, P, N)$. This critical 
distance is determined by a vector $\theta$ that summarizes the expected consumer satisfaction for attending to this movie; the booking for this movie, $P$; and the number of copies, $N$. We assume that the expected consumer satisfaction is a vector of multiple random variables, which could be separated into intra-film characteristics such as genre, sequel, studio, director and actors, previously known booking and prizes, country of origin, publicity, etc.; intra-theater characteristics, such as number of screens and seats, infrastructure and complementary amenities, exhibitor, etc.; and market characteristics such as competitors in the neighborhood, simultaneous releases, weekend, holidays, etc.

We also assume that $Q(\theta, P, N)$ is decreasing on $P$ and not increasing on $N$. It is not increasing on $N$ because as the distributor expects a higher demand for the movie it would increase the number of copies, then in such a case this movie at cinema $A$ will have substitutes from the other $N-1$ cinemas in the same market. To better understand of this assumption, this spatial demand for a movie in a given theater, for $N=1$ and 2 , is explained in Box 1. 
Suppose that theater $\mathrm{A}$ is located at $\mathrm{A}, \mathrm{B}$ at $\mathrm{B}$, etc. If $\mathbf{A}$ is the unique theater that exhibits this film, then its the market by consumers located in the interval [ $A-1 / 2 Q(\theta, P, 1), A+1 / 2 Q(\theta, P, 1)]$. A's rivals do not exhibits the same film (neither a close substitute). Thus, all customers go to $\mathbf{A}$.

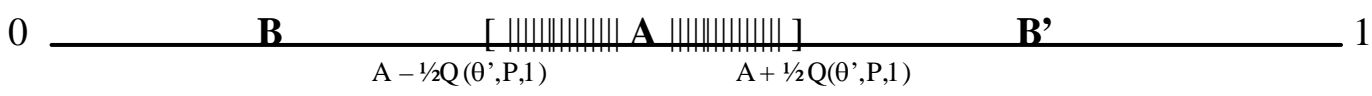

If now $\theta^{\prime}>\theta$, the demand for the movie increases and more consumers go to theater $\mathbf{A}$.

0

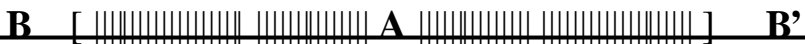

$$
\mathrm{A}-1 / 2 \mathrm{Q}\left(\theta^{\prime}, \mathrm{P}, 1\right) \quad \mathrm{A}+1 / 2 \mathrm{Q}\left(\theta^{\prime}, \mathrm{P}, 1\right)
$$

However, as the expected demand continues increasing to $\theta$ " the distributor may prefer to increase the number of prints for this film. Let us suppose that now that theaters $\mathbf{B}$ and $\mathbf{B}$ ' exhibit this film, then the demand for this film in theater $\mathbf{A}$ fells down even though the global demand for this film increases.

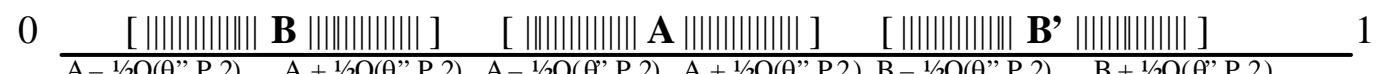

Therefore, it is reasonable to assume that $\mathrm{Q}(\theta, \mathrm{P}, \mathrm{N})$ - a film's demand in each theater - is not increasing on the number of prints.

Spacial demand as $N$ increases

Assuming for simplicity that $N$ is a positive real number, it is reasonable to suppose that $Q(\theta, P, N)$ decreases with $N$. Without loss of generality, we assume that this demand is separable such that $Q(\theta, P, N)=Q_{1}(\theta-P)-Q_{2}(N)$, where $Q_{2}(\cdot)$ is a function increasing on $N$, double and continuously differentiable, and strict convex. ${ }^{4}$ Thus, after adding for $N$ copies-cinemas in the market, the total expected demand for this movie, conditional on $\theta$, is $N\left[Q_{1}(\theta-P)-Q_{2}(N)\right]$.

\footnotetext{
${ }^{4}$ To guarantee existence and uniqueness of an optimal $N$, we suppose that $\frac{\partial Q_{2}(N)}{\partial N}$ goes to 0 (infinite) as $N$ goes to zero (infinite)
} 
Regarding costs and revenues, we assume that each copy of the movie costs $C$, which is a sunk cost for the distributor. Each cinema has operating costs of $c$ for each consumer and a cost of capital $k$, being the last a sunk cost for the owner of the cinema. We also assume that the revenue $P$ is exogenously given and each cinema breaks even, then $c$ is lower than $P$ to cover the sunk cost $k$. If the distributor and the cinema are independent the distributor keeps a share $\alpha$ of the box-office revenue and each cinema gets $(1-\alpha)$.

Finally, we assume that a minimum condition for the release of a movie is that the distributor recovers her investment. Since we already have assumed that each theater's demand is decreasing on $N$, a sufficient condition for the release of a movie is that $\alpha P Q_{1}(\theta-P)>C$.

Next lemma is useful for later results.

Lemma 1 If an independent cinema at least breaks even, then it is true that the Lerner's index in this market is higher than the distributor's box-office share. In other words, $\frac{P-c}{P}>$ $\alpha$.

Proof. The proof of the lemma is straightforward. The fact that an independent cinema gets zero expected profit means $(1-\alpha) P\left[N\left[Q_{1}(\theta-P)-Q_{2}(N)\right]\right]-c\left[N\left[Q_{1}(\theta-P)-Q_{2}(N)\right]\right]-$ $k=0$ or, $(1-\alpha) P-c=\frac{k}{N\left[Q_{1}(\theta-P)-Q_{2}(N)\right]}$. Then it is true that marginal revenue must be above marginal cost to finance the cinema's sunk cost, or $(1-\alpha) P>c$. After some algebra, $\frac{P-c}{P}>\alpha$. 


\subsection{The Main Result: Vertical Integration and the Release of New Films}

Let us assume now that the distributor owns $J$ theaters in this market, with $0 \leq J \leq N$ - The latter inequality condition rules out the necessity for including the decision about other films in this model. ${ }^{5}$ If $N$ is a continuous variable, then the distributor's problem becomes:

$$
\max _{\{N\}} J(P-c)\left[Q_{1}(\theta-P)-Q_{2}(N)\right]+(N-J) \alpha P\left[Q_{1}(\theta-P)-Q_{2}(N)\right]-C N-k J
$$

The first order condition is sufficient given the strict concavity on the objective function.

Thus, after some algebra we get:

$$
Q_{1}(\theta-P)-C=Q_{2}(N)+\frac{\partial Q_{2}(N)}{\partial N}\left[J \frac{P-c}{\alpha P}+N-J\right]
$$

The next proposition shows that there exists a unique $N^{*}$, the optimal number of copies, that solves (1).

Proposition 2 Assume that for a given movie with a vector of characteristics $\theta$ and for some small $N$ it is true that $J(P-c)\left[Q_{1}(\theta-P)-Q_{2}(N)\right]+(N-J) \alpha P\left[Q_{1}(\theta-P)-Q_{2}(N)\right]>$ $C N$. Then there exist $N^{*}$ that maximizes the distributor objective function and this $N^{*}$ is unique.

\footnotetext{
${ }^{5}$ The condition $J<N$ might be obviously incorrect since $N$ is endogenous, but for simplicity assume that for most movies a distributor releases the optimal number of copies satisfies this condition.
} 
Proof. Consider $N=0$. In this case, the right-hand-side of (1) is equal to zero. Then, $Q_{1}(\theta-P)-C>0$.

Consider now $N$ going to infinite. The left-and-side of (1) remains constant but the right-hand-side of (1) goes to infinite because of the conditions that we impose on $Q_{2}(N)$. Then, $Q_{1}(\theta-P)-C<\infty$.

Since $Q_{2}(\cdot)$ is continuous and both $Q_{2}(\cdot)$ and $\frac{\partial Q_{2}(\cdot)}{\partial N}$ are strictly increasing functions, then by the mean value theorem there exists a unique $N^{*}$ that solves (1). This completes the proof.

Finally, using this result and equation (1) we may find the effects on exogenous variables on the optimal number of copies of a film. In particular, our interest is to find the effects on $N^{*}$ of a change on $\theta$ (any change in an intra-film, intra-theater, or a market variable) and $J$, the number of theaters vertically integrated. The next proposition summarizes this comparative static analysis:

Proposition 3 Considering that equation (1) is an identity and assuming that $J\left(\frac{P-c}{\alpha P}-1\right)<$ $N^{*}$, then (i) the effect of any exogenous variable on the consumer satisfaction function have the same sign that its effect on the optimal number of copies, and (ii) the effect of vertical integration on the optimal number of copies is negative. 
Proof. Since $N^{*}$ is unique and solves $Q_{1}(\theta-P)-C=Q_{2}\left(N^{*}\right)+\frac{\partial Q_{2}\left(N^{*}\right)}{\partial N}\left[J \frac{P-c}{\alpha P}+N^{*}-J\right]$ and the vector $\theta$ is exogenous, then it is also true that:

$$
\begin{aligned}
\frac{\partial Q_{1}(\theta-P)}{\partial \theta} & =\frac{\partial Q_{2}}{\partial N^{*}} \frac{d N^{*}}{d \theta}+\frac{\partial^{2} Q_{2}\left(N^{*}\right)}{\partial N^{* 2}} \frac{d N^{*}}{d \theta}\left[J\left(\frac{P-c}{\alpha P}\right)+N^{*}-J\right]+\frac{\partial Q_{2}\left(N^{*}\right)}{\partial N^{*}} \frac{d N^{*}}{d \theta} \\
\frac{d N^{*}}{d \theta} & =\frac{\frac{\partial Q_{1}(\theta-P)}{\partial \theta}}{2 \frac{\partial Q_{1}\left(N^{*}\right)}{\partial N^{*}}+\frac{\partial^{2} Q_{2}\left(N^{*}\right)}{\partial N^{* 2}}\left[J\left(\frac{P-c}{\alpha P}\right)+N^{*}-J\right]}
\end{aligned}
$$

Then, since the denominator is strictly positive, the sign of $\frac{d N^{*}}{d \theta}$ is the same as the sign of $\frac{\partial Q_{1}}{\partial \theta}$, which complete the first part of the proof for the proposition.

The proof of the second part of the proposition is the following. Consider an exogenous change on $J$ :

$$
\begin{aligned}
0 & =\frac{\partial Q_{2}\left(N^{*}\right)}{\partial N^{*}} \frac{d N^{*}}{d J}+\frac{\partial^{2} Q_{2}\left(N^{*}\right)}{\partial N^{* 2}} \frac{d N^{*}}{d J}\left[J\left(\frac{P-c}{\alpha P}\right)+N^{*}-J\right]+\left(\frac{P-c}{\alpha P}-1\right) \frac{\partial Q_{2}\left(N^{*}\right)}{\partial N^{*}} \\
\frac{d N^{*}}{d J} & =\frac{-\left(\frac{P-c}{\alpha P}-1\right) \frac{\partial Q_{2}\left(N^{*}\right)}{\partial N^{*}}}{\frac{\partial Q_{1}\left(N^{*}\right)}{\partial N^{*}}+\frac{\partial^{2} Q_{2}\left(N^{*}\right)}{\partial N^{* 2}}\left[J\left(\frac{P-c}{\alpha P}\right)+N^{*}-J\right]}
\end{aligned}
$$

Since the denominator of this equation is positive and Lemma 1 shows that the numerator of this equation is negative, then the effect of an increase of the vertical integration between a distributor and a theater is to reduce the number of copies of new released films. This completes the proof.

The proposition provides several hypotheses that could be tested empirically, the one on the effect of vertical integration being of particular interest. However, before proceeding to the empirical part of the paper it is useful to show a close form solution for the model and also check the robustness of this proposition to the case in which the distributor faces 
competition from other distributors.

\subsection{An Example that Yields a Close Form Solution}

Assuming that $Q_{1}(\theta-P)-Q_{2}(N)=\theta-P-N^{2}$, the problem of a distributor that owns $J$ theaters is now:

$$
\max _{\{N\}} J(P-c)\left[\theta-P-N^{2}\right]+(N-J) \alpha P\left[\theta-P-N^{2}\right]-C N-k J
$$

and after some algebra, the first order condition of this problem yields the optimal number of copies:

$$
N^{*}=\sqrt{J^{2}\left(\frac{(1-\alpha) P-c}{3 \alpha P}\right)^{2}+\frac{1}{3}\left(\theta-P-\frac{C}{\alpha P}\right)}-J \frac{(1-\alpha) P-c}{3 \alpha P}
$$

which is strictly positive since $\theta-P>\frac{C}{\alpha P}$, otherwise the distributor could not recover the fixed cost of an extra copy of the film.

As can be directly seen from the equation, the optimal number of copies is increasing in $\theta$, the vector of intra-movie, intra-theater and market variables; and decreasing in $J$, the number of cinemas vertically integrated with the distributor $J$, as can be shown by taking 
the derivative of $N^{*}(J)$ with respect to $J$ :

$$
\begin{aligned}
\frac{\partial N^{*}}{\partial J} & =\frac{1}{2} \frac{2 J\left(\frac{(1-\alpha) P-c}{3 \alpha P}\right)^{2}}{\sqrt{J^{2}\left(\frac{(1-\alpha) P-c}{3 \alpha P}\right)^{2}+\frac{1}{3}\left(\theta-P-\frac{C}{\alpha P}\right)}}-\frac{(1-\alpha) P-c}{3 \alpha P} \\
& =\frac{(1-\alpha) P-c}{3 \alpha P}\left(\frac{J((1-\alpha) P-c)}{\sqrt{J^{2}((1-\alpha) P-c)^{2}+3(\alpha P)^{2}\left(\theta-P-\frac{C}{\alpha P}\right)}}-1\right)
\end{aligned}
$$

The expression in parenthesis is negative when the condition to release a film is satisfied, that is $\theta-P>\frac{C}{\alpha P}$. Then, $\frac{\partial N^{*}}{\partial J}<0$ since $(1-\alpha) P$ is greater than $c$, as it was shown in Lemma 1.

\subsection{Robustness: Strategic Competition of Two Distributors}

Let us show that the previous result is robust to a strategic interaction among distributors during the release of new films' decision. Without further loss of generality, assume that two distributors are simultaneously deciding the number of copies for the release of two new films. One of the distributors, say distributor $A$, owns $J$ theaters and the other distributor, say distributor $B$, is not vertically integrated. Also assume, as before, that each theater of distributor $A$ receives the film $\left(J<N_{A}\right.$ for any $N_{A}$ resulting from the distributor $A$ 's decision).

Assuming that both films are perfect substitutes whenever they share the same vector of characteristics $\theta$ (intra-film, intra-theater and market characteristics), then perfect sustitution implies that more copies of one film reduce the demand for the other film. Thus, the demand for the film that distributor $A$ releases is $N_{A}\left[Q_{A}(\theta-P)-Q_{B}\left(N_{A}+N_{B}\right)\right]$, which 
is conditional on the conjecture about the other distributor's decision: $N_{B}$. Therefore, the distributor $A$ 's problem is:

$$
\operatorname{Max}_{N_{A}}\left[J(P-c)+\left(N_{A}-J\right) \alpha P\right]\left[Q_{A}(\theta-P)-Q_{B}\left(N_{A}+N_{B}\right)\right]-C N_{A}-k J
$$

The first order condition for this problem is:

$$
-\frac{\partial Q_{B}\left(N_{A}+N_{B}\right)}{\partial N_{A}}\left[J(P-c)+\left(N_{A}-J\right) \alpha P\right]+\alpha P\left[Q_{A}(\theta-P)-Q_{B}\left(N_{A}+N_{B}\right)\right]=C
$$

Similarly, the demand for the movie that distributor $B$ releases is $N_{B}\left[Q_{A}(\theta-P)-Q_{B}\left(N_{A}+N_{B}\right)\right]$. The distributor's problem is:

$$
\operatorname{Max}_{N_{B}} \alpha P N_{B}\left[Q_{A}(\theta-P)-Q_{B}\left(N_{A}+N_{B}\right)\right]-C N_{B}
$$

The first order condition of this problem is:

$$
-\frac{\partial Q_{B}\left(N_{A}+N_{B}\right)}{\partial N_{B}} \alpha P N_{B}+\alpha P\left[Q_{A}(\theta-P)-Q_{B}\left(N_{A}+N_{B}\right)\right]=C
$$

Let us assume that there exists a unique pair $\left(N_{A}^{*}, N_{B}^{*}\right)$ in equilibrium. Therefore, since $\frac{\partial Q_{B}\left(N_{A}+N_{B}\right)}{\partial N_{A}}=\frac{\partial Q_{B}\left(N_{A}+N_{B}\right)}{\partial N_{B}}$, then equations (2) and (3) yield:

$$
-J \frac{(P-c)}{\alpha P}+N_{B}^{*}=N_{A}^{*}
$$


By Lemma 1, conditional on the intra-movie, intra-theater and market characteristics, the number of copies a vertically integrated distributor releases is lower than the number of copies that an independent distributor releases: $N_{A}^{*}<N_{B}^{*}$. This result is a substitute of the one in Proposition 3 part ii).

Finally, this result should hold if we consider the case in which new releases with different characteristics are simultaneously entering the market. To see this, just consider that the distributor $B^{\prime}$ s film has a vector of characteristics $\theta^{\prime} \neq \theta$. In this case the films are imperfect substitutes and an increase in the number of copies of one film partially reduces the demand for the other film. A parameter $\delta \in(0,1)$ captures this partial reduction on demand. To get a form close solution consider again the previous structure $Q_{1}(\theta-P)-Q_{2}(N)=\theta-P-N^{2}$. Taking into account these assumptions, the problems of both distributors are:

$$
\begin{aligned}
& \operatorname{Max}_{N_{A}}\left[J(P-c)+\left(N_{A}-J\right) \alpha P\right]\left[\theta-P-\left(N_{A}+\delta N_{B}\right)^{2}\right]-C N_{A}-k J \\
& \operatorname{Max}_{N_{B}} \alpha P N_{B}\left[\theta^{\prime}-P-\left(\delta N_{A}+N_{B}\right)^{2}\right]-C N_{B}
\end{aligned}
$$

The first order conditions are:

$$
\begin{array}{r}
-2\left(N_{A}+\delta N_{B}\right)\left[J(P-c)+\left(N_{A}-J\right) \alpha P\right]+\alpha P\left[\theta-P-\left(N_{A}+\delta N_{B}\right)^{2}\right]=C \\
-2\left(\delta N_{A}+N_{B}\right) \alpha P N_{B}+\alpha P\left[\theta^{\prime}-P-\left(\delta N_{A}+N_{B}\right)^{2}\right]=C
\end{array}
$$


After some algebra, we obtain:

$$
-J \frac{(P-c)}{\alpha P}\left(\frac{N_{A}^{*}+\delta N_{B}^{*}}{N_{A}^{*}+N_{B}^{*}}\right)+\frac{\theta-\theta^{\prime}}{2\left(N_{A}^{*}+N_{B}^{*}\right)}=\left(N_{A}^{*}-N_{B}^{*}\right)\left(\frac{2-\delta}{2}\right)
$$

So, for any $\theta^{\prime} \geq \theta$ - the vertically integrated distributor has a smaller or equal expected revenue than the one expected by the independent distributor and it is true that $N_{A}^{*}<N_{B}^{*}$ as before. Only if $\theta>\theta^{\prime}$ is large enough it could be the case that an independent distributor releases less movies than a vertically integrated one.

The following proposition summarizes the discussion for the case of strategic competition:

Proposition 4 Assume that two distributors simultaneously release one film each. Assume also that $Q(\theta, P, N)=Q_{1}(\theta-P)-Q_{2}(N)$. i) If both films share the same vector of characteristics $\theta$ then the vertically integrated distributor releases less prints of its film than the independent distributor, this is $N_{A}^{*}<N_{B}^{*}$. ii) If the vector of characteristics is such that the expected demand for the vertically integrated distributor's film is equal or lower than its rival's expected demand, $\theta^{\prime} \geq \theta$, then still $N_{A}^{*}<N_{B}^{*}$. iii) If $Q(\theta, P, N)=\theta-P-N^{2}$, then only when the vertically integrated distributor expects a considerable higher demand for its film, it could be the case that $N_{A}^{*}>N_{B}^{*}$.

Proof. The proof of this proposition follows from the previous discussion.

As a summary, the hyphotesis to be tested empirically is that the vertical integration between a distributor and a theater, conditional on the expected demand, yields a lower 
number of prints in new released films. The empirical analysis requires then to control for intra-movies, intra-theaters, and market characteristics in order to condition on $\theta$.

\section{Data}

The dataset used in the empirical analysis consists of weekly film-programming data for an average of 30 theaters in 11 major cities in Chile during the period January 2001 December 2004. For each theater, for each week, the data contain information on which films are exhibited at each screen, the weekly revenue generated by each film, and the genre of the film. Additionally, the data includes information about the capacity of each screen, the owner of each theater, the distributor of each film, and the total number of screens used for each film's first week release. Unfortunately, we do not have information about the expenses on advertising by the distributor of the film.

The data contains many interesting features. In many small cities in Chile there used to be only one theater and during the time span covered by the sample a new theater was opened, which allows us to estimate the impact of entry in the market. There is also exit of theaters during this period of time, particularly in the city of Santiago, the largest one in the country. Additionally, among the three main distributors (Fox-Warner, Andes Films, and UIP), one is vertically integrated towards the exhibition market and own several theaters. Finally, based on empirical results showing that Oscar awards matter (Deuchert, Adjamah and Pauly, 2005), we constructed several variables to capture the effect of Oscar nominations and awards each movie received. Table 4 shows a summary of the data. 
Table 4: Summary Statistics

\begin{tabular}{l|ccccc} 
Variable & $\mathbf{N}$ & Average & Stand. Dev. & Min & Max \\
\hline Action & 10.566 & 0,284 & 0,451 & 0 & 1 \\
Adventure & 10.566 & 0,162 & 0,368 & 0 & 1 \\
Comedy & 10.566 & 0,249 & 0,432 & 0 & 1 \\
Horror-Thriller & 10.566 & 0,061 & 0,238 & 0 & 1 \\
Drama & 10.566 & 0,182 & 0,385 & 0 & 1 \\
Crime & 10.566 & 0,056 & 0,230 & 0 & 1 \\
Documentary & 10.566 & 0,005 & 0,071 & 0 & 1 \\
UIP & 10.566 & 0,012 & 0,107 & 0 & 1 \\
Andes Films & 10.566 & 0,027 & 0,163 & 0 & 1 \\
Fox-Warner & 10.566 & 0,271 & 0,444 & 0 & 1 \\
Hoyts & 10.566 & 0,221 & 0,414 & 0 & 1 \\
Showcase & 10.566 & 0,097 & 0,297 & 0 & 1 \\
Cinemundo & 10.566 & 0,166 & 0,372 & 0 & 1 \\
Showtime & 10.566 & 0,024 & 0,155 & 0 & 1 \\
Chilean & 10.566 & 0,064 & 0,244 & 0 & 1 \\
Sequel & 10.566 & 0,152 & 0,359 & 0 & 1 \\
Capacity & 10.566 & 245,49 & 101,86 & 90 & 990 \\
Weekly Premieres & 10.566 & 3 & 2 & 1 & 17 \\
Monthly Premieres & 10.566 & 10 & 4 & 1 & 25 \\
Number of Screens & 10.566 & 29,56 & 12,04 & 1 & 91 \\
Vertically Integrated & 10.566 & 0,064 & 0,243 & 0 & 1 \\
Holiday Week & 10.566 & 0,227 & 0,419 & 0 & 1 \\
Oscar Award Nominations & 10.566 & 0.52 & 1.63 & 0 & 13 \\
Oscar Award Win & 10.566 & 0.01 & 0.08 & 0 & 1 \\
Oscar Award Best Actor/Actress & 10.566 & 0.02 & 0.13 & 0 & 1
\end{tabular}


We created a set of dummies for the genre of the movie (Action, Adventure, Comedy, Horror-Thriller, Drama, Crime, Documentary, and Others $)^{6}$, the distributors (UIP, Andes Films, Fox-Warner, and Independents), the exhibitors (Hoyts, Showcase, Cinemark, Cinemundo, and Independents), Chilean movies and sequels.

The other variables are defined as follows: Capacity is the number of seats of each screen; Weekly Premieres is the total number of new films released in the country each week; Number of Screens is the total number of screens used nationally to release the movie; Vertically Integrated is a dummy equal to one if the distributor of the movie is Andes Films (the only distributor that owns theaters in Chile); Holiday Week is a dummy equal to one if either the week or the weekend in which the movie was released was a national holiday; Oscar award nominations is the total number of nominations received by the film; Oscar Award Win is a dummy equal to 1 if the film won the Oscar for best movie; and Oscar Best Actor/Actress is a dummy equal to 1 if either the leading actor or actress in the film won an Oscar.

\section{Empirical Results}

Table 5 shows the results of the estimation using a negative binomial count model. The dependent variable corresponds to the number of prints of a new released movie in the first-run exhibition market in Chile. We report the estimated coefficient, its standard error, and the marginal effect of each variable on the expected number of copies a distributor

\footnotetext{
${ }^{6}$ These categories are the ones used by the distributors in Chile.
} 
Table 5: Negative Binomial Estimation

\begin{tabular}{|l|l|ll}
\hline Variable & Coefficient & Std. Error & Marginal Effects \\
\hline Capacity & 0.00029 & 0.00004 & 0.0069 \\
Action & 2.54785 & 0.18559 & 14.139 \\
Adventure & 2.57902 & 0.18584 & 21.627 \\
Comedy & 2.25082 & 0.18561 & 11.921 \\
Horror-Thriller & 2.44044 & 0.18598 & 20.748 \\
Drama & 2.07520 & 0.18568 & 11.182 \\
Crime & 2.28230 & 0.18603 & 17.611 \\
Documentary & 1.54365 & 0.19251 & 8.634 \\
Chilean & 0.32911 & 0.01693 & 9.069 \\
Sequel & 0.17681 & 0.01329 & 4.512 \\
Holiday Week & 0.00913 & 0.00993 & 2.160 \\
Weekly Premieres & -0.01442 & 0.00243 & -0.342 \\
Monthly Premieres & -0.01699 & 0.00119 & -0.403 \\
Oscar Award Nominations & 0.19991 & 0.01200 & 5.044 \\
Oscar Award Wins & 0.03303 & 0.02003 & 0.773 \\
Oscar Award Best Actor/Actress & 0.07662 & 0.03583 & 1.888 \\
Vertically Integrated & -0.28494 & 0.07242 & -7.821 \\
Constant & 0.89430 & 0.18607 & \\
\hline N & 10178 & \\
\hline log pseudo-likelihood & -37298.6 & \\
\hline Wald & 23572.15 & \\
\hline
\end{tabular}

releases. ${ }^{7}$

All variables related to the genre of the movie (action, adventure, comedy, etc.) are positive and strongly significant. The marginal effects imply that, on average, Adventure, Horror-Thriller and Crime films have the more expected return to the distributors in Chile since more prints of these genres are released (around 21 more copies with respect to the "Other" genre, the omitted category consisting mostly of local and arthouse movies). The Comedy, Drama and Documentary genres are released with a much lower number of copies

\footnotetext{
${ }^{7}$ We also estimated a Poisson count model, which is more restrictive since it assumes equidispersion, but the overdispersion test suggested by Cameron and Trivedi (1990) rejects the equidispersion assumption.
} 
(around 11 copies more than Other genre).

A sequel is released with around 5 more copies than a non sequel film. Even though not all sequels are as successful as the first film, the result is consistent with a higher expected return given the success of the original film. Not only the distributor has more information about the expected box-office of the sequel because the attendance of the original film is known, but also the fact that the studios decided to produce a sequel of the film signals a more probability of success. In the case in which there are no higher expectations, probably the sequel will be distributed directly to either the pay-per-view or the DVD market.

Regarding the importance of the Chilean cinema for a distributor, the results show that a Chilean movie has almost 8 more copies released that a movie from abroad, everything else constant. It is not clear, however, if this result reflects a stronger preference of the public for Chilean movies, the effects of many subsidies provided by the government during the last 5 years to the production and distribution of Chilean films, or just a marketing strategy of larger chain exhibitors: they always have to exhibit a local movie.

The empirical results also show that if a film faces more competition when it is released the distributor reduces the number of copies, as the coefficients of the variables Weekly premieres and Monthly premieres are negative and significant. The marginal effects are not large in magnitude however, if 10 more movies are released the same week the number of copies is reduced by 3 and if 10 more movies are released the same month the number of copies distributed of the film decrease by 4 .

Distributors, in general, expects higher admissions in holiday weeks, such as Christmas, 
Independence Day, Schools' winter vacations, etc. A film release in a holiday week has 2 more prints, on average, everything else constant. Since the magnitude in not as large as expected, a possible explanation is that intra-film competition is more important in explaining the number of prints, since the distributor is more concerned with how the films performs in the first-run market (survival) rather than in an specific weekend. Alternatively, people in large markets (cities) leave taking advantage of the holidays and, therefore, the expected box-office is not much higher than on regular weeks.

Finally, and the most important result given the goal of the paper, a distributor who owns a chain of theaters releases 8 less prints of a film than independent distributors, everything else constant. This empirical result is consistent with the theoretical results derived before.

\section{Conclusions}

This paper explores the effect of vertical integration, between an exhibitor and a distributor in the motion-picture industry, on the release of new films. For this purpose, a simple but robust model is build to determine the different incentives a distributor faces when integrated and when non-integrated. The model predicts a negative impact of the vertical market structure on the number of prints a distributor releases of a new film. This theoret-

ical result is then tested using a rich data set of the motion-pictures exhibition market in 11 major cities in Chile over a period of 6 years.

After controlling for several film and market characteristics, the empirical results show 
that an integrated distributor releases, on average, around 8 less copies of a film than a non-integrated distributor. Future research should address if this effect on the released pattern of new films is efficient or reflects the use of market power.

\section{References}

Agostini, C. and E. Saavedra (2006), "Survival in the Motion-Picture Exhibition Market in Chile", Documento de Investigación I-22, ILADES-Universidad Alberto Hurtado.

Bagella, M. and L. Becchetti (1999), "The Determinants of Motion Picture Box Office Performance: Evidence from Movies Produced in Italy", Journal of Cultural Economics $23(4)$.

Canterbery, E.R. and A. Marvasti (2001), "The U.S. Motion Picture Industry: An Empirical Approach", Review of Industrial Organization 19.

Chisholm, D. and G. Norman (2006), "When to Exit a Product: Evidence from the U.S. Motion-Pictures Exhibition Market", American Economic Review, Papers and Proceedings $96(2)$.

Chisholm, D., M. McMillan, and G. Norman (2006), "Product Differentiation and Film Programming Choice: Do First-Run Movie Theaters Show the Same Film?", Working Paper 12646 NBER.

Corts, K. (2001), "The Strategic Effects of Vertical Market Integration Structure: Common Agency and Divisionalization in the US Motion Picture Industry", Journal of Economics 85 Management Strategy 10(4). 
De Vany, A.S. and W.D. Walls (1996), "Bose-Einstein Dynamics and Adaptative Contracting in the Motion Picture Industry", Economic Journal 106.

De Vany, A.S. and W.D. Walls (1997), "The Market for Motion Pictures: Rank, Revenue, and Survival", Economic Inquiry 35.

Deucher, E., K. Adjamah, and F. Pauly (2005), "For Oscar Glory or Oscar Money?", Journal of Cultural Economics 29(3).

Fu, W.W. (2009), "Screen Survival of Movies at Competitive Theaters: Vertical and Horizontal Integration in a Spatially Differentiated Market", Journal of Media Economics $22(2)$

Gil, R. (2007), "", "Make or Buy in Movies: Integration and Ex-post Renegotiation", International Journal of Industrial Economics 25(4).

Goettler, R.L. and P. Leslie (2005), "Cofinancing to Manage risk in the Motion Picture Industry", Journal of Economics 83 Management Strategy 14(2).

Hand, C. (2001), "Increasing Returns to Information: Further Evidence from the UK Film Market", Applied Economics Letters 8.

Jansen, C. (2005), "The Performance of German Motion Pictures, Profits and Subsidies: Some Empirical Evidence", Journal of Cultural Economics 29(3).

Walls, W.D. (2005), "Modeling Movie Success when Nobody Knows Anything: Conditional Stable-Distribution Analysis of Films Returns", Journal of Cultural Economics $29(3)$. 